\title{
ERRATUM TO: THE GENERALIZED DINA MODEL FRAMEWORK
}

\author{
JIMMY DE LA TORRE
}

RUTGERS, THE STATE UNIVERSITY OF NEW JERSEY

\section{Erratum to: Psychometrika (2011) 76:179-199 \\ DOI 10.1007/s11336-011-9207-7}

The article "The Generalized DINA Model Framework" reported an item stem from the Millon Clinical Multiaxial Inventory-III (MCMI-III) in the process of illustrating some modeling results using real data on the MCMI-III. While this item content is available on the Pearson Assessments website, the item stem should not have appeared in the article, and we regret the error. All authors must obtain permission to publish item content for copyrighted test material prior to submitting an article for publication at Psychometrika. 